\title{
O Lugar da Pesquisa na Formação Docente no Ensino a Distância no Curso de Licenciatura em Geografia
} The Place of Research in Teaching Training in Distance Learning in the Geography Degree Course

\author{
Rodrigo Batista Lobato*1 \\ Vanilda M.S.Teofilo \\ 1 Universidade Federal do Rio de \\ Janeiro - Avenida Athos da Silveira \\ Ramos, 274, Cidade Universitária, llha \\ do Fundão, Rio de Janeiro, RJ, Brasil. \\ rodrigolobato.geo@gmail.com \\ 2 Universidade do Estado do Rio de \\ Janeiro. Rua São Francisco Xavier, \\ 524, Maracanã, Rio de Janeiro, RJ, \\ Brasil.
}

\section{Resumo}

O presente estudo tem como objetivo central apontar o lugar da pesquisa ao longo da formação docente no ensino a distância (EaD), desenvolvendo o estudante em sua graduação, não somente para ministrar aulas de sua ciência em específico, mas também para que este discente veja na pesquisa uma forma de gerar conhecimento. Os caminhos metodológicos dessa pesquisa percorreram três etapas: a primeira consiste na pesquisa bibliográfica, visando subsidiar a compreensão do sentido professor-pesquisador. Na segunda etapa, foi realizada uma análise no currículo do curso de Licenciatura em Geografia da UERJ, na modalidade EaD, com o intuito de observar como esse currículo tem efetivamente dado lugar à pesquisa na formação do professor de Geografia. A terceira e última etapa está calcada no acompanhamento de dez discentes, a partir de 2013, e o resultado de suas pesquisas culminaram em monografias defendidas até o ano de 2019, corroborando com a formação docente obtida na graduação em EaD. Como resultado, pode-se constatar o crescimento acadêmico desses dez discentes, desde o ingresso dos mesmos no curso de graduação, especialmente pelo fato de o currículo ofertar uma disciplina teórico-prática em cada período da grade curricular, disciplinas estas voltadas para uma prática científica do licenciando de Geografia. Constata-se que as mesmas vêm contribuindo em muito na formação desse futuro professor-pesquisador, acrescida naturalmente da fase de orientação para os trabalhos de conclusão de curso. Por fim, todos os estudantes, em suas monografias, mostraram-se pesquisadores, buscando desenvolver temas voltados para a sua prática pedagógica com uma visão ressignificada de professor, no que tange à sua atuação no magistério, compreendendo que o docente não tem apenas que reproduzir o conteúdo, mas buscar possibilidades para mediar o conhecimento em sala de aula a partir do resultado de suas pesquisas.

Palavras-chave: Professor-pesquisador. Formação docente. Graduação a distância. 


\title{
The Place of Research in Teaching Training in Distance Learning in the Geography Degree Course
}

\begin{abstract}
The main objective of this study is to point out the place of research throughout the distance learning (DE) teacher education, developing the student in his graduation, not only to teach specific science classes, but also for this student see research as a way to generate knowledge. The methodological paths of this research covered three stages: the first consists of bibliographic research aiming to support the understanding of the teacher-researcher meaning. In the second stage, an analysis was carried out on the curriculum of the Geography Degree course at UERJ, in the distance learning modality, in order to observe how this curriculum has effectively given rise to research in the education of the Geography teacher. The third and last stage are based on the monitoring of ten students, starting in 2013, and the results of their research culminated in monographs defended until 2019, corroborating the teacher training obtained in undergraduate distance education. As a result, we can see the academic growth of these ten students, since their entry into the undergraduate course, especially because the curriculum offers a theoretical-practical discipline in each period of the curriculum, disciplines aimed at a scientific practice of the undergraduate student of Geography. It appears that they have been contributing a lot in the formation of this future research teacher, naturally added to the orientation phase for the course conclusion works. Finally, all students in their monographs showed themselves to be researchers seeking to develop themes aimed at their pedagogical practice with a reframed view of the teacher, with regard to their performance in the teaching profession, understanding that the teacher does not only have to reproduce the content, but look for possibilities to mediate knowledge in the classroom based on the results of their research.
\end{abstract}

Keywords: Professor-researcher. Teacher training. Distance graduation.

\section{Introdução}

Vivenciamos, na atualidade, uma modernidade líquida, como sugere Baumam (2001), na qual o tempo não somente aparenta estar mais rápido em relação aos cronômetros, mas, sobretudo, pelas relações sociais estarem cada vez mais fluidas e com um processo acelerado de individualização. Cabe-nos, ainda, fazer um paralelo com Harvey (1989) em seu conceito de compressão tempo-espaço para falar dessa modernidade líquida. Assim, será utilizada, nesta reflexão, o termo cotidiano para se falar da escola, tal como é usado por Alves (2019).

Nesse enredo, o artigo em questão visa refletir o sentido dicotômico professor-pesquisador que conclui a graduação, de modo que essa relação não é dialógica na prática, após esse egresso se inserir no magistério, realidade essa diferente dos docentes inseridos no Ensino Superior, baseada na tríade ensino, pesquisa e extensão.

A indagação trazida é em relação ao profissional formado na graduação e que irá atuar no Ensino Fundamental Il e Ensino Médio. Assim, essa reflexão não está se debruçando nos profissionais voltados para uma formação de pesquisador stricto sensu, como aqueles que cursam o doutorado, ou abordando os docentes no magistério superior. 
Fora dessa etapa do ensino, que não faz parte da Educação Básica, é preciso considerar algumas instituições de ensino que garantam ao professor, em suas atribuições, o exercício da docência, pesquisa e extensão, como no caso do Colégio Pedro II e dos Institutos Federais.

No trato da realidade, as demais escolas, com poucas ressalvas, criam a dicotomia professor-pesquisador, de maneira que ela não se coloque como sendo um local para gerar conhecimento, mas onde esse conhecimento é reproduzido.

Diante disto, o objetivo central deste artigo é apontar o lugar da pesquisa ao longo da formação docente, desenvolvendo o estudante em sua graduação não somente para ministrar aulas de sua ciência em específico, mas também para que o mesmo considere a pesquisa como uma forma de gerar conhecimento.

Entendemos que um espaço de formação de professores forme também pesquisadores, e este profissional irá gerar conhecimento a partir de um método científico. Todavia, os atos de preparar e ministrar aulas, apesar de diferentes da pesquisa, são indissociáveis.

Para enfrentar o desafio proposto, face às questões diretamente relacionadas à experiência no campo da educação, tomamos como ponto de partida o lugar ocupado - o de docente e orientador de monografia na formação de professores.

Nesta perspectiva, com base nas múltiplas experiências em Educação e enquanto formadores de licenciados, trabalhando num espaço que define as políticas de formação e atuando na coordenação de tutoria e mediação do curso de Geografia, na modalidade a distância, somado à expertise de coordenação dos tutores, é possível constatar que alguns espaços formativos ainda têm dificuldade em perceber a importância de garantir, nos currículos e programas acadêmicos, a integração de diferentes áreas de conhecimento. Além disso, inclui-se a experiência de estar inserido na modalidade a distância desde 2013, ministrando tutoria presencial e a distância, além da orientação de monografias no período apontado.

Para assegurar uma formação sintonizada com os desafios e exigências de uma sociedade cada vez mais global e mutável, torna-se necessário e fundamental a integração das diferentes áreas de conhecimento e a sua consequente articulação dos saberes, ajudando ao futuro docente a compreender a importância de um olhar e uma postura constante de pesquisador.

É importante ressaltar que esforços deverão ser empregados no sentido de alimentar e aprofundar os debates a respeito da importância e do lugar que a pesquisa ocupa nos cursos de formação docente, especialmente se considerarmos que vivemos um período marcado pela transitoriedade e mudanças bruscas, não se esquecendo da multiplicidade de fenômenos a serem levados em conta ao se caracterizar os sujeitos que transitam na escola contemporânea.

Nesta direção, o objetivo deste artigo é apresentar os egressos de Geografia sendo (res)significados de meros professores a professores-pesquisadores, resultado este que pode ser observado a partir dos projetos de monografia do curso a distância de Licenciatura em Geografia da Universidade do Estado do Rio de Janeiro, a partir da seleção de dez trabalhos, nos quais evidenciamos não somente um projeto autoral monográfico, mas uma formação docente que permita a esse estudante formar-se com esta perspectiva - a de que ele é um professor-pesquisador e que a sua pesquisa subsidiará a sua prática docente.

\subsection{O sentido e a função social da escola e a relação teoria/prática nos espaços escolares}

Ao constatarmos que algo vem ocorrendo na relação entre o estudante, o professor e o conhecimento, que impede a escola de cumprir o seu papel social, torna-se real a exigência de uma ruptura com esses 
processos convencionais. Uma escola preocupada em educar sujeitos individuais, que serão adaptados a um meio pré-determinado, não vai dar conta da pluralidade de sujeitos que hoje nela transitam.

Ao concentrarmos nossa atenção na escola, a quem se delega a função de ajudar na formação dos indivíduos, observa-se claramente que ela vem cumprindo seu papel social numa perspectiva extremamente conservadora.

Esse caráter conservador pode facilmente ser constatado, especialmente quando analisamos o paradigma que Mizucami (1986) nos apresenta: uma visão tradicional de ensino, cabendo ao professor transmitir verdades prontas, absolutas e inquestionáveis para indivíduos alienados e alijados do ponto de vista cultural, contribuindo, dessa forma, com a reprodução das desigualdades sociais.

As teorias formuladas segundo as orientações da cultura científica trouxeram uma grande contribuição para a escola, na medida em que mostraram não darem conta de formar um sujeito, que não é mais um sujeito cartesiano, da razão, da prática, individual e isolado, mas, ao contrário, um sujeito que interage com o seu meio.

As mudanças ocorridas na sociedade contemporânea afetam a rotina das pessoas, suas condições de vida, trazendo consequências para a formação da identidade do sujeito "pós-moderno"; daí, a necessidade de "rearranjos nas relações e nos contextos de experiência social" (MANCEBO, 2003).

Para tanto, é necessário que nossas práticas educativas caminhem na busca constante de novas formas de relação, que exigem o reconhecimento da complexidade dos fatos e fenômenos de uma sociedade contemporânea, deslocando o eixo educativo para os processos de construção, o sujeito cognoscente e a rede social na qual esse conhecimento está distribuído, a fim de "assegurar a inclusão de todos numa escola para todos" (SENNA, 2003).

Há escolas que ainda se organizam num paradigma fechado, assentado na cultura científica (YUS, 2002; SENNA 2003), trabalhando com conceitos incontestáveis, e a formação técnica do professor, por algum motivo, não o habilita para atuar no magistério, e o contexto sociocultural não entra em diálogo com a cultura científica.

Para que os espaços escolares assumam seu papel de agente formador, a fim de dar conta dessa pluralidade de sujeitos, é preciso considerar que a integração desses discentes implica um redesenho da escola, tendo esta que investir em políticas e programas que contribuam para o desenvolvimento do entendimento, da solidariedade e tolerância entre indivíduos e grupos, implementando um esforço no sentido de que todos percebam que a multiculturalidade é uma realidade e que a tolerância à diversidade é algo necessário.

Contrariamente à lógica formal, cartesiana e linear, que nos acompanhou até o séc. XIX, essa nova era exige, por parte de estudiosos e pesquisadores da realidade social, uma atenção e até uma recondução da "nave de pesquisa" para além do contexto, que, com suas inovações, incertezas, fragmentações, fazem com que essas marcas fragilizem as práticas de construção de conhecimento.

Em consequência da história da educação, temos como forte herança na educação o método indutivo, cuja origem está no pensamento dominante do séc. XIX, evidenciado na doutrina positivista de Comte. Essa marca tão presente nas práticas educativas traz uma concepção de aluno-sujeito do processo de aprendizagem e de professor como mediador do conhecimento, visando, sem dúvida, a uma aprendizagem centrada no indivíduo.

Tanto a repetida defesa da abordagem comportamental da escola tecnicista quanto a abordagem tradicional restringiram-se à aplicação de um ensino prático, que exige um planejamento, que, para a cultura científica, é não só desejável como relevante. Foi esta redução de uma práxis à técnica que favoreceu a crise do paradigma da ciência moderna e sua degenerescência, que justificam a crítica à epistemologia cartesiana (SANTOS, 1989). 
O ideal de homem a ser educado, que incorpora os valores de produção, exige a compreensão de que esses valores não são específicos da escola porque foram instituídos pela sociedade. É esse desvelamento que permitirá o real entendimento da natureza social da escola e que parece ser um ponto de confluência das abordagens tradicional e tecnicista, ao defenderem como sendo valores capazes de contribuir para a construção do conhecimento (VALLE, 1987).

As políticas educacionais são, para Brinhosa (2002), materializadas a partir das exigências do mundo de produção, expropriando o saber nos mais diferentes níveis e graus de ensino, inviabilizando a participação coletiva, impedindo que os sujeitos se apropriem da cultura letrada.

Em outros termos, tem o sentido de dizer que, ao estudar a escola contemporânea, uma proposta de "desfragmentação da Ciência" (BRINHOSA, 2002) se apresenta, a qual está assentada na monocultura e no rigor do saber, conforme Boaventura (2004), pois inviabiliza a possibilidade de outros caminhos, outras formas de desenvolver saberes mais coerentes com a sala de aula.

Nesse sentido, caberia lembrar a teoria histórico- cultural de Lev Semionovitch Vigotski, que nos ajuda a compreender a importância dos aspectos históricos e culturais no processo de formação, como aponta Prestes (2010). A esse respeito, as pesquisas de Kramer (1986) também confirmam que:

As crianças são seres sociais, e não apenas seres psicológicos ou em desenvolvimento, em crescimento, em evolução (por mais que concordemos com o fato de que há evidentemente uma evolução biopsicológica universal). Dizer que a criança é um ser social significa dizer que ela tem uma história, que vive uma geografia, que pertence a uma classe social determinada, que estabelece relações definidas segundo seu contexto de origem, que apresenta uma linguagem decorrente dessas relações sociais e culturais estabelecidas, que ocupa um espaço que não é só geográfico, mas também de valor, ou seja, ela é valorizada de acordo com os padrões do seu contexto familiar e de acordo também com a sua própria inserção nesse contexto.

Lembraríamos ainda de Freire (2003, p.159):

Saber melhor significa precisamente ir além do senso comum, a fim de começar a descobrir a razão de ser dos fatos [...], começando de onde as pessoas estão, ir com elas além desses níveis de conhecimento sem transferir o conhecimento.

De modo que esse autor já tinha o discernimento de que o professor precisa levar em consideração, na mediação do saber, o conhecimento das crianças, o que entende-se aqui como letramento(s), embora ainda não fosse usado esse conceito tal como apontaram as autoras Soares (2009) e Rojo (2009).

Por outro lado, a proposta da abordagem tradicional e a dimensão crítico-social dos conteúdos têm em comum o fato de que ambas desconsideram que os conceitos trabalhados nas disciplinas, enquanto conteúdos que partem de verdades que se instalam na cultura científica, não possibilitam a aprendizagem e o desenvolvimento dos sujeitos cuja verdade esteja à margem dessa cultura.

Tem-se, assim, o modelo de educação tradicional, que vem sendo questionado desde o séc. XIX (ALVES, 1999), e que está assentado na forma como os modos de produção se organizavam. Visa a um saber prático e tem como finalidade a formação de pessoas para o mercado de trabalho. Na verdade, é um caminho que vem sendo apresentado como possibilitador de acesso à escola, mas que, pela sua "seleção a-natural" (ALVES, 1999, p.116), continuará excluindo os sujeitos da cultura oral. 


\subsection{O professor-pesquisador nos espaços escolares}

Como destacado no item anterior, a escola não está dando conta de se descolar da concepção de sujeito individual-racional, pensante e consciente - o sujeito cartesiano, para uma "concepção mais social de sujeito", menos localizado e definido (HALL, 2001). Neste sentido, a escola não acompanhou, em seu desenvolvimento, a passagem do sujeito-cartesiano, sujeito-científico, para o sujeito-social e sujeito-oral.

Um novo horizonte epistemológico, ou seja, um modelo mais amplo e aberto e, consequentemente, diferente do modelo positivista que ainda vigora hoje, seria condição fundamental para essa passagem; daí, a importância de se discutir os métodos, a função e o sentido da escola, pois até hoje não damos conta dos sujeitos plurais que nela transitam e, por esta razão, continuamos atrasados.

Um sistema fechado, inflexível, no qual predomina a técnica, não valorizando os processos de construção, inviabiliza e indisponibiliza as condições necessárias ao aprender, dificultando ao professor a busca de pontos de confluência, interface entre diferentes saberes, não permitindo o diálogo com sujeitos não científicos, não dando conta da singularidade e pluralidade que temos em nossa cultura. Um saber único, que se encaixe num único conceito de verdade, não faz mais sentido na contemporaneidade.

Estamos, portanto, diante de uma exigência: provocar uma ruptura com o que está posto e acordar para um outro projeto de educação numa prática pedagógica dialógica. Trabalhar nesse sentido reflete investir numa escola que potencializa um sujeito em operação, um sujeito que, com seu potencial e experiência, será capaz de se aproximar do contexto cultural, produzindo pensamentos e pensando o mundo de forma diferente daquela que os educadores imaginam ou imaginavam.

A possibilidade de cruzar dois universos - o da Ciência e o do senso comum propugnada por Santos (2004), ainda tão desejada no nosso ponto de vista, só será possível mediante uma postura e uma prática de pesquisa por parte do docente, o que viabiliza, sem dúvida, uma nova realização de interdependência entre teoria e prática.

Esta é a razão pela qual é preciso que o educador, enquanto sujeito e autor de um saber, compreenda que as práticas educativas têm de estar hoje em constante diálogo com a sala de aula, pois sabemos ser a relação teoria/prática o elemento alavancador da construção de saberes, sendo a coerência entre ambas de fundamental importância.

Nesse contexto, a literatura referente à pesquisa aponta ser esta uma prática fundamental no desenvolvimento profissional do professor e no desenvolvimento curricular. O termo prático reflexivo, que na década de 1990 gerou bastante debate, surgiu com Zeichner (1998), que afirmava que o constante diálogo e a verdadeira articulação teoria/prática são condições fundamentais para que ocorra essa prática.

Uma vez aceita e incorporada a concepção de professor reflexivo e pesquisador, evidencia-se a importância de assumi-la como um instrumento e uma prática reflexiva constantes.

Concordamos com Lewis (1997), de que existem diferentes visões pessoais de mundo em função dos diferentes sujeitos que nele transitam - o que significa sustentar que o sujeito social se forma pela subjetividade que ele vai construir, construção esta que será da responsabilidade das vivências dos próprios sujeitos e dos espaços sociais, de modo que o humano conduz o seu desenvolvimento tomando elementos do meio, que é social e historicamente construído (VIGOTSKI, 2010).

Desta forma, tudo o que se supunha como fixo, coerente e estável passou a ser apresentado de diferentes formas, num contexto de incertezas e dúvidas. As mudanças são de tal ordem que, muitas vezes, sequer pensamos sobre elas, sendo que uma das características deflagradas na contemporaneidade foi a chamada crise de identidade, num contexto social marcado pelo relativismo, pela provisoriedade, pela incerteza, pelo imprevisível, pelas contradições, pela descentração e deslocamento do sujeito. 
Durante toda a nossa vida, trabalhamos com certezas, com regras e normas centradas em valores pré-determinados pela ordem da cultura moderna, cabendo à escola um papel de destaque em sua perpetuação. Hoje, todavia, as informações externas são mais contundentes e múltiplas do que aquelas construídas no lócus escola, e, diante dessa realidade, pergunta-se: Como deverá ser a formação do professor?

Trabalhar com os sujeitos contemporâneos sugere compreender outro papel para o professor, que não é, com certeza, o de transmissor de conteúdo, esperando depositar no aluno tudo o que professa como uma verdade a ser reproduzida infinita e irrecorrivelmente, tal como denunciou Freire (2005), ao chamar isso de Educação Bancária. O professor terá que estabelecer uma relação amistosa com a pluralidade de conhecimentos disponíveis, pois sua função será basicamente a de organizar as informações, pesquisar e investigar, devendo ser aquele que aprende a aprender e ensina a aprender.

\section{Metodologia}

Os caminhos metodológicos dessa pesquisa possuem três etapas. A primeira consiste na pesquisa bibliográfica para subsidiar a compreensão do sentido de professor-pesquisador. Como segunda etapa, foi realizada uma análise no currículo do curso de Licenciatura em Geografia da UERJ, na modalidade EaD, no qual observamos como esse currículo tem dado lugar à pesquisa na formação do professor de Geografia. A terceira e última está calcada no acompanhamento de 10 discentes, a partir de 2013, e o resultado de suas pesquisas, que culminaram em monografias defendidas até o ano de 2019, corroborando com a formação docente obtida na graduação em EaD.

\section{Resultados e Discussão}

\subsection{Breve análise da matriz curricular do curso de Geografia da UERJ na modalidade EaD}

Como parte do objeto de estudo desta pesquisa, foi analisada a matriz curricular do curso de Licenciatura em Geografia da UERJ, na modalidade EaD, como pode ser observado nas disciplinas Teoria e Prática em Geografia, Prática e Pesquisa em Geografia e Monografia, que irão favorecer o estudante a se tornar um professor-pesquisador, pois, em todos os períodos, os discentes são submetidos a essa forma científica de pensar através do olhar da ciência geográfica.

A disciplina de Teoria e Prática em Geografia (TPG), por sua vez, se mantém ao longo da grade curricular durante todo o curso, de modo que esse futuro professor de Geografia vai buscar compreender a Geografia para além de sua teoria, incluindo seu uso cotidiano.

Em outras palavras, o professor ${ }^{1}$ de cada disciplina de TPG, em seu respectivo período, fará essa correlação entre teoria e prática por um viés científico. Vale destacar três pontos dessa disciplina: ela possui uma sequência na grade curricular, isto é, TPG I ocorrendo no primeiro período; TPG II, no segundo, e assim vai até o final, com a TPG VIII no último período.

O primeiro ponto é o fato de que essas disciplinas submeterão os discentes a olharem para essa correlação teoria e prática para além de uma dicotomia - de forma dialógica e natural, ou seja, dando embasamento teórico para a prática geográfica. O segundo é o formato desenvolvido, pois busca capacitar os estudantes a terem um olhar voltado para a sala de aula, porém, com as atividades realizadas no formato científico, incentivando a pesquisa, conforme as regras da ABNT.

1 O curso de licenciatura em Geografia da UERJ possui um professor para cada disciplina em sua matriz curricular e, desta forma, a disciplina de TPG possui oito professores diferentes ao longo do curso. 
Finalmente, no terceiro e último ponto, a disciplina TPG VII, alocada no sétimo período e que antecede o projeto de monografia, visa ser o início da pesquisa do trabalho de conclusão de curso, de modo que os discentes estarão escolhendo seus orientadores, que será dada continuidade no semestre seguinte, na disciplina de Monografia.

Quanto à disciplina Teoria e Prática em Geografia VIII, oferecida no oitavo período, vale a ressalva de que possui um objetivo diferente em relação às disciplinas de TPG anteriores, pois trabalha, com as formas de avaliação, o processo da aprendizagem na escola, a importância do trabalho de campo, as orientações para uma articulação entre teoria com o espaço percebido dos escolares na prática do trabalho de campo.

Devemos ter em mente que a disciplina de Monografia é a culminância desse processo formador, e segue na sequência do trabalho de pesquisa realizado no período anterior com Teoria e Prática em Geografia VII. É desejável que a continuidade da pesquisa monográfica seja preferencialmente com o mesmo orientador de TPG VII, com esta orientação sendo realizada por um mediador a distância ou através de um mediador presencial em um dos polos do CEDERJ.

A monografia, antes da sua defesa, passa por uma avaliação da coordenação de monografia e mais dois docentes. Tendo um parecer favorável, o discente poderá agendar com o seu orientador a defesa, com apresentação para uma banca, cumprindo toda a liturgia acadêmica. Cabe ainda abordar uma questão importante, a disciplina Prática e Pesquisa em Geografia ocorre no quarto período do curso, de maneira que a ementa está assim descrita:

\begin{abstract}
Aplicação prática dos temas geográficos em estudos de casos específicos. A disciplina será organizada a partir de questões atuais que envolvem determinado recorte espacial previamente escolhido pelo professor e, a partir daí, os alunos, com orientação docente, executarão a práxis com trabalho de campo. Desenvolvimento de um trabalho de diagnóstico e/ou avaliação em todas as suas fases, desde a abordagem do tema, passando pela discussão metodológica, coleta de dados primários, até a elaboração de um relatório final. Desenvolvimento da autonomização do futuro profissional de Geografia na produção de um projeto de pesquisa. (GEOGRAFIA - UERJ EaD, 2013).
\end{abstract}

A discussão metodológica com coleta de dados e a elaboração de relatório final para apresentar os resultados são oriundas de um projeto de pesquisa. É notório aqui a demonstração do caráter científico para a prática docente, tendo em vista que a ementa da disciplina Prática e Pesquisa em Geografia aponta para uma "aplicação prática dos temas geográficos em estudos de casos específicos".

Cabe ressaltar que as ementas são interdependentes, todas preocupadas com o caráter científico do ponto de vista de fornecer lugar à pesquisa, estando as mesmas voltadas para a formação do docente pesquisador. Mas devemos tomar cuidado para não cairmos no erro de achar que somente essas disciplinas possuem caráter científico.

E nisso, é preciso reconhecer que as disciplinas propedêuticas da Geografia e suas respectivas Atividades à Distância (AD2) fornecem um caráter científico também, sobretudo para os estudantes realizarem suas pesquisas em cada tarefa solicitada.

2 As Atividades a Distância (AD) são trabalhos que os discentes fazem ao longo do semestre em cada disciplina. Esses trabaIhos somam pontos com a nota da prova. Vale lembrar que, diferentemente das ADs, as provas são aplicadas presencialmente em cada polo do CEDERJ. 


\subsection{Pesquisas desenvolvidas na graduação}

Por conseguinte, destinamos também trazer alguns resultados obtidos desse processo de formação e ressignificação de um professor-reprodutor para um professor-pesquisador em um curso a distância. Diferentemente da modalidade presencial, a qual possui fisicamente diversos espaços voltados para a pesquisa, com diversos estudantes sendo introduzidos a uma iniciação científica, o curso EaD é voltado para um público que não pode estar presencialmente na universidade.

Apesar disso, sabemos que o perfil do estudante EaD vem mudando, e ratificamos a importância em abordar essa temática que é muito relevante para compreender os motivos desse público-alvo estar em mudança, ou seja, fazendo a ressalva de que este assunto, ainda que importante ao presente artigo, não será aqui abordado.

Sendo assim, ao perceber que grande parte dos orientandos apresentasse essa característica, ou seja, a de trabalhar e não ter disponibilidade para fazer parte de um grupo de pesquisa, surge a pergunta que norteou esse trabalho: será que esse currículo é capaz de fornecer essa visão de pesquisador, além da profissão no magistério?

Na tentativa de escutar o campo, fizemos o acompanhamento de dez discentes de turmas diferentes, nessa jornada acadêmica a distância, de maneira que foi possível perceber o amadurecimento de cada um deles, sendo preciso dizer que não estará padronizada a curva de aprendizagem de todos, pois uns mostraram maior rapidez no desenvolvimento acadêmico que outros - o que é compreensível.

Todos esses dez estudantes trabalhavam, e quanto ao gênero, eram cinco mulheres e cinco homens. É imperioso dizer que apenas um deles conseguiu concluir o curso no tempo de quatro anos, o que não foi possível com os demais, com a justificativa de terem que se inscrever em menos disciplinas, ao longo dos semestres, para darem conta de suas atividades fora da graduação.

O estudante mais novo, na pesquisa, estava com vinte e dois anos e, o mais velho, sessenta e quatro. Em relação ao mais velho, a sua demora em se formar se deu também pelo fato de ele ter ficado desempregado durante um ano.

Estar ocioso do trabalho não significou que ele pudesse ter feito mais disciplinas para terminar logo a graduação, pois a busca para se recolocar no mercado de trabalho consumia tempo, energia e gerava preocupações a ele. O fato de não ter despesas com deslocamento, durante a semana, foi um fator determinante para que o mesmo não trancasse a sua matrícula e pudesse acompanhar de casa, embora esse estudante atrasasse a sua conclusão do curso. Faz-se importante relatar esse evento, para que entendamos o perfil de estudante do qual estamos falando.

Dentre os títulos das pesquisas desenvolvidas e o ano de defesa, estão:

1. A importância da Geografia na Educação Infantil - 2017;

2. Uso da corrida de orientação como atividade prática de Cartografia no Ensino Médio - 2018;

3. Uso do recurso didático AR Sandbox com alunos do Ensino Médio com Alfabetização Cartográfica incipiente - 2018;

4. O Ensino de Geografia para alunos com deficiência visual: Estudo de caso na Escola Municipal Darcílio Ayres Raunheitti - Município de Nova Iguaçu - RJ - 2018;

5. O sentido de mapa dos desenhos animados infantis - 2018;

6. Mapeamento das salas de cinema dos bairros do subúrbio carioca como formas simbólicas espaciais - das ruas ao shopping center - de 1906 até os dias de hoje - 2019; 
7. Trajetória da formação de professores de Geografia no Brasil e o ensino de africanidades nas escolas - 2019;

8. A utilização de aplicativos e games disponibilizados para dispositivos móveis como ferramenta facilitadora no ensino aprendizado da Geografia - 2019;

9. A fotografia como recurso pedagógico para educação cartográfica: Uma proposta para o Ensino Fundamental II - 2019;

10. O ensino da Cartografia a partir do Google Earth para alunos do NEJA: CIEP 075, no bairro de Jardim Cabuçu, Nova Iguaçu - RJ - 2019.

Durante o processo de construção da pesquisa do trabalho de conclusão de curso - em paralelo com acompanhamento do orientador -, foi possível apresentar dois posters em eventos de iniciação científica, além de um artigo científico. Após a conclusão da pesquisa, e como resultado das mesmas, foram publicados cinco artigos científicos.

Desses dez egressos, sete afirmaram querer continuar com a sua formação continuada para a docência, trabalhando com essa característica na pesquisa e almejando uma pós-graduação stricto sensu, buscando também atuação no magistério. Desses sete, dois já realizaram curso de pós-graduação lato sensu.

\section{Conclusão}

Dentre os dez estudantes que desenvolveram suas pesquisas, vale dizer que a modalidade a distância forçou os mesmos a buscarem disciplina para realizarem suas leituras ao longo de sua formação. Essa organização foi fator fundamental, inclusive, uma condição de autonomia nos estudos.

Tal afirmação se dá ao percebermos que as leituras indicadas na orientação não eram somente lidas, mas os estudantes também traziam outros artigos para serem discutidos durante a orientação das monografias.

É imperioso destacar o crescimento que esses estudantes tiveram após o processo de orientação, somado com o comprometimento que eles já possuíam. Como o próprio nome sugere, a orientação não remete que o pesquisador em formação não saiba pesquisar, mas que esse estudante é acompanhado por alguém que já passou por essa etapa e que também seja um especialista no assunto em estudo.

Nas pesquisas aqui apresentadas, os pesquisadores buscaram desenvolver temas voltados para a sua prática pedagógica, o que retrata que essa pesquisa visa à sua atuação no magistério.

Finalmente, torna-se fundamental compreender a evolução dos alunos, que antes tinham um pensamento e uma expectativa bem diferentes com relação à formação de um licenciando em Geografia, muitas vezes, na expectativa de serem reprodutores de conhecimento. Todavia, todo esse processo de formação vivenciado ao longo do curso foi (re)significado e permitiu a todos entenderem que é preciso desenvolver habilidades e competências para que possamos realizar pesquisas de caráter científico e aplicá-las nas práticas docentes, tornando-os verdadeiros professores pesquisadores

\section{Agradecimentos}

Agradecemos ao curso de Licenciatura em Geografia da UERJ, inserido no consórcio CEDERJ. Estende-se essa gratidão aos atuais professores-pesquisadores, que transformaram o processo de orientação nessa modalidade a distância em um grupo de pesquisa, que fez uso das novas tecnologias de informação e comunicação para crescermos juntos em nossa prática pedagógica no ensino de Geografia. 


\section{Referências}

ALVES, N. G. Práticas pedagógicas em imagens e narrativas: memórias de processos didáticos e curriculares. 1. ed. São Paulo: Cortez, 2019

ALVES, N.; e GARCIA, R. (orgs). O sentido da escola. Rio de Janeiro. DP\&A, 1999.

BAUMAN, Z. Modernidade líquida. Rio de Janeiro: Zahar, 2001.

BRINHOSA, M. A função social e pública da educação na sociedade contemporânea. In: LOMBARDI, José C. (org) Globalização, pós-modernidade e Educação-história, filosofia e temas transversais. Campinas, Autores Associados, 2002.

FREIRE, P. Cartas a Cristina: reflexões sobre minha vida e minha práxis. $2^{\text {a }}$ ed. São Paulo: UNESP, 2003.

FREIRE, P. Pedagogia do oprimido. Rio de Janeiro: Paz e Terra, 2005.

GEOGRAFIA UERJ EAD. Ementa das Disciplinas do Curso de Licenciatura em Geografia UERJ. CECIERJ, Rio de Janeiro, [s.d.]. Disponível em: https://www.cecierj.edu.br/wp-content/uploads/2019/09/Ementas-das-disciplinas-Geografia-UERJ.pdf. Acesso em: 20 de nov. de 2019.

HALL, S. Nascimento e morte do sujeito moderno. In: Identidade cultural na Pós-Modernidade. Trad. Portuguesa. Rio de Janeiro, DP\&A, 2001.

HARVEY, D. A condição pós-moderna. São Paulo: Atlas, 1989.

KRAMER, S. O Papel Social da Pré-Escola. Cadernos de Pesquisa (Fundação Carlos Chagas. Impresso), v. 58, p. 77-81, 1986.

LEWIS, M. Modelos tradicionais de mudança. In: Alterando o destino - porque o passado não prediz o futuro. Tradução Portuguesa. São Paulo, Moderna/UNICAMP, 1997.

LIBÂNEO, J. C. Por uma pedagogia crítica que ajude na formação de sujeitos pensantes e críticos. In: LINHARES, Célia et al. Os lugares dos sujeitos na pesquisa educacional. Campo Grande, UFMT, 2002.

MANCEBO, D. Contemporaneidade e efeitos da subjetivação. In: Psicologia e compromisso social. São Paulo. Cortez, 2003

MIZUCAMI, M. G. Abordagem tradicional. In: Ensino: as abordagens do processo. São Paulo, E.P.U.,1986.

PRESTES, Z. Quando não é quase a mesma coisa: Análise de traduções de Lev Semionovitch Vigotski no Brasil. Repercussões no campo educacional. UNB: Brasília, 2010.

SANTOS, B. S. Conhecimento Prudente para uma Vida Decente. São Paulo: Cortez, 2004.

SENNA, L. A. G. Notas de aula proferidas no curso de Doutorado nas disciplinas Seminário de Consolidação, Metaforização, 2003.

VALLE, L. Sob o modo de criação: a escola pública imaginária. In: A escola imaginária. Rio de Janeiro, DP\& ${ }^{a}, 1987$

VIGOTSKI, L.S. Aprendizagem e desenvolvimento na Idade Escolar. In: Linguagem, desenvolvimento e aprendizagem. Vigostky, L. Luria, A. Leontiev, A.N. 11ª. Edição. São Paulo: Ícone, 2010.

YUS, R. H. (org) “Educação Integral e valores da não - violência”.In: Revista Pátio, 21/ Maio/Julho, 2002.

ZEICHNER, K. Para além da divisão entre professor pesquisador e pesquisador acadêmico. In: GERALDI, Corinta: FIOENTINI, Dario e PEREIRA, E.M. de A.(orgs)Cartografias do trabalho docente: Professor(a)pesquisador(a). Campinas: ALB/Mercado de Letras, PP.207-236 (Coleção Leituras do Brasil). 